\title{
PENDEKATAN ANALISIS VECTOR AUTO REGRESSION (VAR) DALAM HUBUNGAN HARGA SAHAM SEKTOR INFRASTRUKTUR DAN MANUFAKTUR
}

\author{
Wahyuni Windasari \\ Program Studi Manajemen STIE Putra Bangsa \\ Jl.Ronggowarsito 18 Kebumen, wahyuwindasari@gmail.com
}

\begin{abstract}
ABSTRAK
Penelitian ini bertujuan untuk melihat ada-tidaknya hubungan antara harga saham di sektor infrastruktur dan sektor manufaktur dengan menggunakan model VAR. Adapun data yang digunakan berupa data harga saham harian pada sektor infrastruktur dan manufaktur periode Januari 2015- Juli 2017 sebanyak 661 data dengan olah data menggunakan software Eviews. Dari hasil penelitian menunjukkan bahwa harga saham sektor manufaktur mempengaruhi saham sektor infrastruktur sesuai dengan model VAR(2). Selanjutnya dari uji Portmanteau diperoleh bahwa model VAR(2) merupakan model terbaik untuk menjelaskan hubungan antara harga saham sektor infrastruktur dan harga saham sektor manufaktur.
\end{abstract}

Kata Kunci : VAR, saham, infrastruktur, manufaktur.

\begin{abstract}
This research aims to explain the relationship between stock price in the infrastructure and manufacturing sectors with VAR models. The data used is daily stock price data period Januari 2015 until July 2017 as many as 661 sampel. In this research, the software used to analyze the data is Eviews. In this case, the results of the causality test in second lag indicates that the stock price in manufacturing sector affects the stock price in infrastructure sector. Obtained by result of Portmanteau test indicated that model of VAR (2) is the best model to explain the relationship of stock price in the infrastructure and manufacturing sectors.
\end{abstract}

Keyword $\quad$ : VAR, stock, infrastructure sector, manufacturing sector. 


\section{Pendahuluan}

Menurut data Badan Pusat Statistik, jumlah penduduk Indonesia tahun 2015 mencapai 255.461.686 jiwa. Jumlah ini menempatkan Indonesia pada posisi keempat negara dengan populasi terpadat di dunia. Pertumbuhan penduduk yang semakin meningkat setiap tahunnya ini mendesak pemerintah untuk melakukan percepatan pembangunan infrastruktur Indonesia. Pemerintah menargetkan sampai dengan tahun 2019 akan membangun 52 proyek jalan tol sepanjang 1000 kilometer di seluruh Indonesia.

Kebijakan pemerintah pada sektor infrastrukur ini tentunya berdampak pada pilihan investor dalam melakukan pilihan investasinya. Terdapat sekitar 24 perusahaan yang menjadi produsen beton di Indonesia yang sudah mencatatkan sahamnya di Bursa Efek Indonesia, diantaranya Waskita Beton Precast (WSBP) dan Wijaya Karya Beton (WTON). Kapasitas produksi WSBP pada tahun 2015 sebesar 1,8 juta dan melejit di tahun 2016 mencapai 2,65 juta ton. Sedangkan untuk kapasitas produksi WTON tercatat sebanyak 2,34 juta ton di tahun 2015 dan 2,5 juta ton di tahun 2016. Pertumbuhan perusahaaan beton tersebut berdampak pada saham-saham di sektor infrastruktur seperti WIKA, WSKT
WSBP, dan WTON menjadi sahamsaham pilihan di sektor infrastrukur. Selain saham di sektor infrastruktur yang menggeliat naik, saham di sektor manufaktur yang merupakan penyedia bahan-bahan industri dasar dan kimia yang menopang sektor infrastruktur juga menjadi imbas dari kebijakan pemerintah di bidang infrastruktur ini. Hal ini menarik untuk dilakukan penelitian guna melihat ada tidaknya hubungan timbal balik antara harga saham di sektor infrastuktur dan sektor manufaktur sebagai akibat dari kebijakan pemerintah di bidang infrastrukur.

\section{Metode Penelitian}

Metode penelitian yang digunakan dalam penelitian ini adalah analisis keterkaitan antar variabel dengan menggunakan model Auto Regression (VAR). Model VAR berguna untuk meramalkan variabel-variabel, terutama di bidang ekonomi baik untuk jangka panjang ataupun menengah serta untuk menentukan hubungan timbal balik (interrelationship) antara variabelvariabel ekonomi ataupun dalam pembentukan ekonomi yang berstruktur. Pada dasarnya analisis VAR dapat dipadankan dengan suatu model persamaan simultan karena dalam analisis ini mempertimbangkan beberapa variabel 
endogen (terikat) secara bersama-sama dalam suatu model. Dengan kata lain, masing-masing variabel selain diterangkan oleh nilai variabel tersebut di masa lampau juga dipengaruhi oleh nilai masa lampau dari variabel lainnya yang menjadi pengamatan.

Dalam pemodelan menggunakan VAR, terdapat beberapa hal yang perlu diperhatikan antara lain kestasioneritasan data dan lag optimal. Adapun tahapantahapan dalam pemodelan VAR adalah :

\section{Identifikasi Model}

Tahap awal untuk melakukan pemodelan VAR adalah dengan mengidentifikasi model, apakah data time series yang digunakan sudah stasioner baik dalam waktu, rata-rata, maupun variansi. Jika data sudah stasioner dalam tingkatan level maka data asli sudah langsung dapat diestimasi dalam bentuk model VAR biasa (unrestricted VAR). Jika data belum stasioner, maka terdapat 2 kemungkinan yaitu (1) Melakukan differencing pada data asli sehingga data menjadi stasioner dan selanjutnya melakukan estimasi model VAR pada tingkatan difference (VAR in diference form). (2) Tidak melakukan differencing tetapi merestriksi VAR dengan persamaan kointegrasi sehingga diperoleh model Vector Error Correction Model (VECM). Untuk pengujian stasioneritas ini dapat dilihat dari bentuk plot datanya maupun dengan uji Augmented Dickey Fuller $(\mathrm{ADF})$.

\section{Uji Kointegrasi}

Model VAR dapat diterapkan apabila terdapat sejumlah variabel yang mengandung unit root dan tidak berkointegrasi satu dengan yang lainnya.

Uji kointegrasi diperlukan apabila stasioneritas data berada pada tingkat first difference. Pada dasarnya uji kointegrasi ini digunakan untuk melihat keseimbangan jangka panjang diantara variabel-variabel yang diamati. Suatu data yang secara individu tidak stasioner, namun ketika dihubungkan secara linear data tersebut menjadi stasioner atau sering dikenal dengan sebutan terkointegrasi.

Untuk menguji adanya kointegrasi dapat dilakukan dengan menggunakan metode uji Engle-Granger maupun Uji Johansen. Uji ini berupa uji unit root terhadap residual $e_{t}$ yang diperoleh pada persamaan regresi antara variabel-variabel pengamatan. Variabel-variabel tersebut dikatakan berkointegrasi apabila hipotesis adanya unit root ditolak.

\section{Uji Lag Optimum dan Stabilitas}

Ketepatan dalam menentukan panjang lag dan kestabilan estimasi model VAR sangat diperlukan dalam pemodelan VAR karena hubungan kausalitas pada 
model VAR sangat peka terhadap waktu. Untuk menentukan panjang lag optimal pada model VAR dapat menggunakan Akaike Information Criteria (AIC) yang diperoleh dari nilai perhitungan AIC yang memberikan nilai terkecil. Adapun perhitungan AIC diberikan dalam persamaan berikut :

$$
A I C=\ln \left(\frac{R S S}{n}\right)+\frac{2 k}{n}
$$

dengan :

RSS : Banyak residual kuadrat (residual sum of squares)

k : Banyak parameter yang diestimasi

n : Banyak observasi.

Selanjutnya untuk uji kestabilan estimasi model VAR dapat dilakukan pengecekan kondisi VAR stability berupa roots of characteristics polynomial. Suatu sistem VAR dikatakan stabil apabila nilai modulus yang dihasilkan kurang dari satu.

\section{Uji Kausalitas}

Hubungan kausalitas atau sebab akibat antar variabel endogen (terikat) di dalam model VAR dapat diuji dengan menggunakan uji kausalitas Granger. Terdapat tiga kemungkinan dari hasil uji kausalitas Granger yaitu (1) Variabel X menyebabkan (granger cause) Y, (2) Variabel Y menyebabkan (granger cause) $X$, (3) X dan Y memiliki hubungan timbal balik. Dengan kata lain, $\mathrm{X}$ menyebabkan
$\mathrm{Y}$ dan pada saat yang bersamaan $\mathrm{Y}$ menyebabkan $X$. Adapun model persamaan umum untuk kausalitas Granger adalah sebagai berikut:

$$
Y_{t}=\sum_{i=1}^{m} \alpha_{i} Y_{t-i}+\sum_{i=1}^{m} \beta_{i} X_{t-i}+\varepsilon_{1 t}
$$

dengan :

$Y_{t} \quad$ : Nilai variabel Y pada waktu ke-t

$m$ : Banyak lag

$\alpha_{i} \quad$ :Koefisien dari lag ke-i dari variabel $\mathrm{Y}$

$\beta_{i} \quad$ :Koefisien dari lag ke-i dari variabel $\mathrm{X}$

$X_{t-i}$ :Nilai variabel $X$ pada lag ke-i, dengan $\mathrm{t}$ lebih besar dari $\mathrm{i}$

$\varepsilon_{1 t} \quad$ : Error pada waktu ke-t

\section{Estimasi Model VAR}

Model Vektor Autoregressive (VAR) merupakan sistem persamaan dimana setiap variabel sebagai fungsi linier dari konstanta dan nilai lag (lampau) dari variabel itu sendiri serta nilai lag dari peubah lain yang ada dalam sistem persamaan. Model ini dibangun dengan pertimbangan meminimalkan pendekatan teori dengan tujuan agar mampu menangkap fenomena ekonomi dengan baik.

Pada model VAR, seluruh variabel diperlakukan sebagai variabel endogen (variabel terikat). Asumsi yang harus dipenuhi dalam metode VAR adalah 
semua variabel tak bebas harus bersifat stasioner (mean, variansi, dan covarian bersifat konstan) serta semua sisaan bersifat white noise yang artinya memiliki nilai rataan nol, ragam konstan, dan saling bebas.

Bentuk umum model VAR (p) dengan $k$-variabel endogen $y_{t}=\left(y_{1 t}\right.$, $\left.y_{2 t}, \ldots, y_{k t}\right)$ dapat dituliskan sebagai :

$$
y_{t}=A_{1} y_{t-1}+\cdots+A_{p} y_{t-p}+C D_{t}+u_{t}
$$
dengan :

$A_{i}$ : Matriks koefisien berdimensi (k x k),

$$
\mathrm{i}=1,2, \ldots, \mathrm{p}
$$

C : Matriks koefisien dari m-variabel independen yang mungkin masuk ke dalam model dengan dimensi $\mathrm{k} \mathrm{x} \mathrm{m}$

$D_{t}$ : Vektor kolom berdimensi $\mathrm{m} \times 1$ yang memuat semua variabel independen yang mungkin masuk ke dalam model, seperti konstanta, trend, variabel dummy dan atau variabel dummy musiman.

$u_{t}$ : Proses white noise berdimensi $\mathrm{k}$.

\section{Uji Diagnostik}

Setelah menentukan model VAR (p) yang sesuai dengan data, langkah selanjutnya adalah melakukan uji diagnostik atau kecocokan dari model. Uji diagnostik ini dapat dilakukan dengan menggunakan uji Portmanteau dengan hipotesis null tidak ada korelasi dari residual model sampai lag ke $h$ bernilai nol.

\section{Hasil dan Pembahasan}

\section{Jenis dan Sumber Data}

Data yang digunakan dalam penelitian ini berupa data sekunder yang diperoleh dari yahoo finance berupa data saham harian di sektor infrastruktur dan manufaktur periode Januari 2015September 2017 sebanyak 661 data.

\section{Analisis Data}

Untuk olah data menggunakan software Eviews. Adapun hasil analisis yang diperoleh adalah sebagai berikut :

1. Identifikasi Model

Untuk melihat kestasioneritasan data dapat dilihat dari plot data asli dari harga saham infrastruktur dan manufaktur.

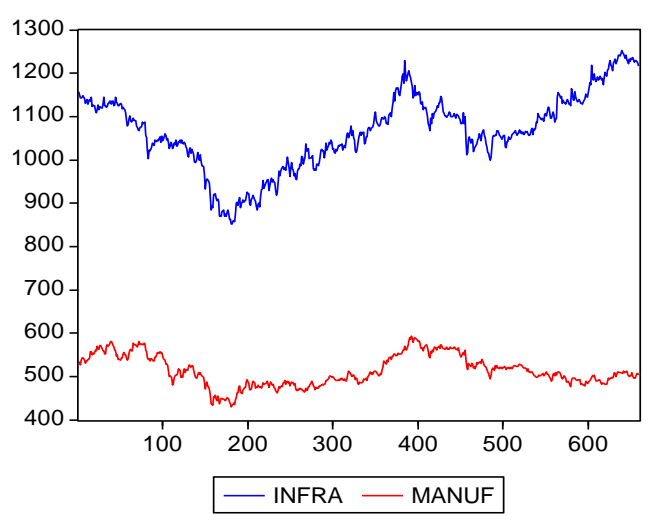

Gambar 1. Plot Harga Saham

Sektor Infrastruktur dan Manufaktur Periode Januari 2015- September 2017. Dari Gambar 1 terlihat bahwa data harga saham sektor infrastruktur dan manufaktur belum stasioner baik dalam 
mean maupun varians. Hal ini dipertegas dengan uji akar-akar unit dengan metode ADF.

Tabel 1. Uji Akar-Akar Unit

Data Harga Saham

\begin{tabular}{|c|c|c|}
\hline Variabel & Nilai ADF & $\begin{array}{c}\text { Critical } \\
\text { Value } 5 \%\end{array}$ \\
\hline Saham & -2.03 & -3.42 \\
\hline \multicolumn{3}{|c|}{ Manufaktur } \\
\hline Saham & -2.36 & -3.42 \\
\hline
\end{tabular}

Nilai statistik uji ADF baik untuk harga saham manufaktur maupun harga saham infrastuktur kurang negatif dibandingkan dengan daerah kritisnya. Hal ini menunjukkan bahwa hipotesa nol adanya akar unit dalam data (data tidak stasioner) diterima.

Selanjutnya untuk menstabilkan data maka dilakukan differencing pada data asli. Dari hasil pembedaan pertama, diperoleh data yang sudah stasioner. Hal ini dapat ditunjukkan dari nilai ADF pada data pembedaan pertama sebagai berikut :

Tabel 2. Uji Akar-Akar Unit

Data Differencing Harga Saham

\begin{tabular}{|c|c|c|}
\hline Variabel & Nilai ADF & Critical \\
\hline Saham & -24.125 & -3.42 \\
\hline \multicolumn{3}{|l|}{ Manufaktur } \\
\hline$\Delta \quad$ Saham & -26.833 & -3.42 \\
\hline
\end{tabular}

Karena diperoleh kedua data stasioner pada proses diferensi pertama, maka perlu dilakukan uji kointegrasi untuk menguji apakah data mempunyai hubungan jangka panjang. Untuk pengujian kointegrasi menggunakan uji Engle-Granger yang memberikan hasil hipotesa null adanya unit root diterima pada tingkat signifikansi 5\%, yakni statistik uji $\mathrm{ADF}=-1.04$ tidak lebih negatif dibandingkan nilai kritisnya sebesar -1.94. Dapat disimpulkan variabel harga saham sektor manufaktur dan harga saham sektor infrastruktur tidak berkointegrasi, sehingga model VAR dapat diterapkan untuk situasi ini.

2. Uji Lag Optimum dan Stabilitas Model

Pemilihan panjang lag yang optimal didasarkan pada nilai AIC yang paling minimum. Output hasil analisis uji lag optimum diberikan pada tabel berikut: Tabel 3. Nilai AIC

$\begin{array}{cc}\text { Lag } & \text { AIC } \\ \mathbf{0} & 13.591 \\ \mathbf{1} & 13.594 \\ \mathbf{2} & 13.589 \\ \mathbf{3} & 13.593 \\ \mathbf{4} & 13.601 \\ \mathbf{5} & 13.602 \\ & \\ \text { Berdasarkan output di atas menunjukkan } \\ \text { bahwa nilai AIC paling minimum berada } \\ \text { di lag ke dua sehingga untuk analisis data }\end{array}$


selanjutnya menggunakan lag ke dua atau dalam bentuk VAR (2).

Selanjutnya dilakukan uji stabilitas estimasi model VAR (2). Dari hasil output eviews diperoleh hasil uji kestabilan sebagai berikut :

\begin{tabular}{|c|c|}
\hline \multicolumn{2}{|c|}{ VAR Stability Condition Check } \\
\hline $\begin{array}{l}\text { Roots of Characteristic } \\
\text { Endogenous variables: } \\
\text { Exogenous variables: C } \\
\text { Lag specification: } 12 \\
\text { Date: } 10 / 30 / 17 \text { Time: }\end{array}$ & MANUF) \\
\hline Root & Modulus \\
\hline $\begin{array}{c}-0.156139-0.251054 i \\
-0.156139+0.251054 i \\
0.146923-0.226401 i \\
0.146923+0.226401 i\end{array}$ & $\begin{array}{l}0.295647 \\
0.295647 \\
0.269896 \\
0.269896\end{array}$ \\
\hline
\end{tabular}

No root lies outside the unit circle.

VAR satisfies the stability condition.

Gambar 3. Output Uji Kestabilan

Model VAR (2)

Dari nilai modulus cek yang kurang dari satu, dapat disimpulkan bahwa model VAR(2) untuk data harga saham sektor manufaktur dan infrastruktur sudah stabil.

\section{Uji Kausalitas}

Uji kausalitas digunakan untuk mengetahui ada tidaknya hubungan timbal balik antara kedua variabel. Penarikan kesimpulan dari uji kausalitas digunakan nilai probabilitasnya. Jika nilai probabilitas kurang dari 5\% maka $H_{0}$ ditolak. Dengan kata lain, dapat disimpulkan bahwa terdapat hubungan kausal antara dua variabel endogen tersebut.

Berikut disajikan nilai $F_{\text {stat }}$ dan probabilitas hasil uji kausalitas Granger.

\begin{tabular}{|c|c|c|c|}
\hline $\begin{array}{l}\text { Pairwise Granger Causality Tests } \\
\text { Date: } 10 / 29 / 17 \text { Time: } 13: 31 \\
\text { Sample: } 1661 \\
\text { Lags: } 2\end{array}$ & & & \\
\hline Null Hypothesis: & Obs & F-Statistic & Probability \\
\hline $\begin{array}{l}\text { MANUF does not Granger Cause INFRA } \\
\text { INFRA does not Granger Cause MANUF }\end{array}$ & 659 & $\begin{array}{l}4.51277 \\
1.15704\end{array}$ & $\begin{array}{l}0.01131 \\
0.31506\end{array}$ \\
\hline
\end{tabular}

Gambar 4. Output Uji Granger Causality

Terlihat bahwa harga saham manufaktur granger cause (mempengaruhi) harga saham infrastruktur akan tetapi tidak berlaku sebaliknya dengan taraf signifikansi sebesar 5\%.

\section{Estimasi Model VAR}

Dari hasil estimasi parameter untuk model VAR (2) diperoleh hasil sebagai berikut : 
Tabel 4. Estimasi Parameter

Model VAR (2)

$\Delta$

\section{Infrastruktur}

$\begin{array}{cc}\Delta \text { Infrastruktur }_{(t-1)} & -0.089153 \\ \Delta \text { Infrastruktur }_{(t-2)} & -0.015456 \\ \Delta \text { Manufaktur }_{(t-1)} & 0.176292 \\ \Delta \text { Manufaktur }_{(t-2)} & -0.172417 \\ \text { Konstanta } & 0.124355\end{array}$

Diperoleh persamaan untuk model VAR(2) adalah :

$\Delta$ Infrastruktur $=0.124355$

- $0.089153 \Delta$ Infrastruktur $_{(t-1)}$

$-0.015456 \Delta$ Infrastruktur $_{(t-2)}$

$+0.176292 \Delta$ Manufaktur $_{(t-1)}$

$-0.172417 \Delta$ Manufaktur $_{(t-2)}$

Pada tahap terakhir dalam analisis model VAR adalah melakukan diagnostic check terhadap model $\operatorname{VAR}(2)$ dengan menggunakan uji Portmanteau.

Adapun output untuk uji Portmanteau diberikan sebagai berikut :

\begin{tabular}{|c|c|c|c|c|c|}
\hline Lags & Q-Stat & Prob. & Adj Q-Stat & Prob. & df \\
\hline 1 & 0.026751 & $\mathrm{NA}^{*}$ & 0.026792 & $\mathrm{NA}^{*}$ & $\mathrm{NA}^{*}$ \\
\hline 2 & 0.133351 & $N A^{*}$ & 0.133717 & $\mathrm{NA}^{*}$ & $\mathrm{NA}^{*}$ \\
\hline 3 & 6.940799 & 0.1391 & 6.972344 & 0.1374 & 4 \\
\hline 4 & 9.532747 & 0.2994 & 9.580144 & 0.2957 & 8 \\
\hline 5 & 16.02791 & 0.1900 & 16.12504 & 0.1856 & 12 \\
\hline 6 & 19.78723 & 0.2300 & 19.91895 & 0.2239 & 16 \\
\hline 7 & 21.66785 & 0.3588 & 21.81980 & 0.3504 & 20 \\
\hline 8 & 25.78379 & 0.3642 & 25.98639 & 0.3539 & 24 \\
\hline 9 & 26.64786 & 0.5375 & 26.86245 & 0.5257 & 28 \\
\hline 10 & 31.54768 & 0.4893 & 31.83788 & 0.4748 & 32 \\
\hline 11 & 36.01928 & 0.4677 & 36.38550 & 0.4507 & 36 \\
\hline 12 & 36.62476 & 0.6230 & 37.00223 & 0.6060 & 40 \\
\hline
\end{tabular}

*The test is valid only for lags larger than the VAR lag order. $\mathrm{df}$ is degrees of freedom for (approximate) chi-square distribution

Gambar 5. Output Uji Kecocokan Model
Dari nilai $\mathrm{p}$-value untuk statistik Q-stat diperoleh bahwa model hipotesis nol tidak ditolak pada tingkat signifikansi $5 \%$, atau dengan kata lain model VAR (2) merupakan model yang baik untuk mengetahui hubungan timbal-balik antara data harga saham sektor infrastruktur dan manufaktur. Hasil ini dapat pula dikonfirmasi dari plot ACF residual untuk model VAR (2) yang menunjukkan residual untuk model VAR bagi data harga saham sektor manufaktur dan sektor infrastruktur tidak mengandung korelasi serial.
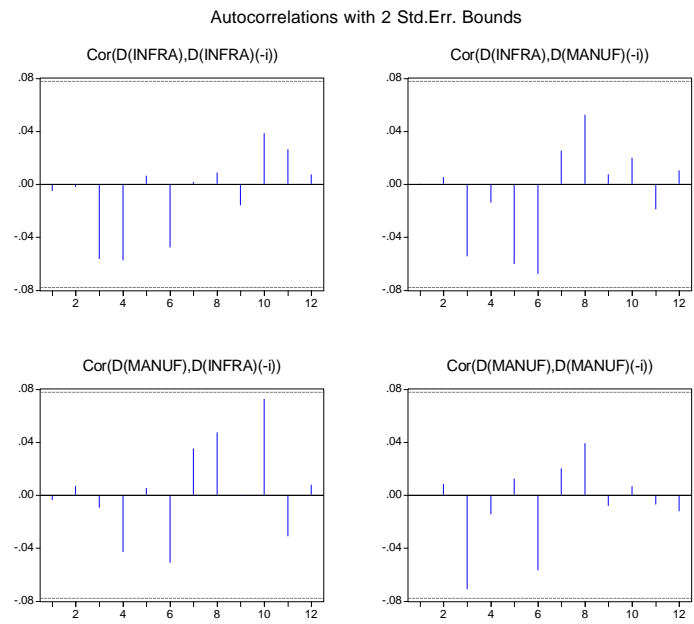

Gambar 6. Plot ACF residual model $\operatorname{VAR}(2)$

\section{Kesimpulan}

Dari hasil pembahasan dapat disimpulkan :

1. Dari hasil uji kausalitas dapat disimpulkan bahwa harga saham 
sektor manufaktur mempengaruhi harga saham sektor infrastruktur.

2. Model terbaik untuk menggambarkan hubungan antara harga sektor manufaktur dan infrastuktur adalah VAR (2).

\section{Pustaka}

Ansofino, dkk, 2016, Buku Ajar Ekonometrika, Yogyakarta : Deepublish.

Gujarati, N. Damodar, 2003, Ekonometrika Dasar, New Jersey: Prentice Hall.

Hadiyatullah, 2011, Model Vector Autoregressive (VAR) dan Penerapannya Untuk Analisis Pengaruh Harga MIGAS Terhadap Indeks Harga Konsumen (IHK). Yogyakarta : UNY.

http://idx.co.id/id-

id/beranda/unduhdata/ringkasan.a $\underline{\text { spx }}$, diakses tanggal 29 September 2017.

http://m.detik.com/finance/market-

research/3434777/saham-

konstruksi-terimbas-

pembangunan-infrastruktur, diakses tanggal 10 Oktober 2017. http://m.kontan.co.id/lipsus/read/216/Sah am-infrastruktur-masih-menjadiprimadona, diakses tanggal 1 Oktober 2017.
Rosadi, Dedi, 2010, Analisis Ekonometrika \& Runtun Waktu Terapan dengan Eviews, Yogyakarta : ANDI.

Suharsono, Agus dan Wibisono, Aryo, 2016, Pemodelan Harga Saham BLUE CHIP Menggunakan Vector Autoregressive (VAR), Madura : Jurnal Performance. 
